\title{
AS CONTRIBUIÇÕES DAS FEIRAS DE CIÊNCIAS PARA A PROMOÇÃO DO DIÁLOGO SOBRE EDUCAÇÃO AMBIENTAL
}

\author{
Michelle Mendes ${ }^{1}$ \\ Rodrigo Arantes Reis ${ }^{2}$ \\ Emerson Joucoski ${ }^{3}$
}

\begin{abstract}
Resumo: O presente artigo busca identificar as discussões ocorridas para a temática ambiental durante as edições da Feira de Ciências do Litoral do Paraná. Este evento ocorre anualmente, e teve início no ano de 2011, a partir da implantação da política educacional para a promoção e discussão do desenvolvimento científico nas escolas públicas do Brasil. Participam da Feira do Litoral Paranaense estudantes de seis municípios que compõem toda a região litorânea. A partir de dados iniciais notou-se que, em ampla medida, a busca por projetos de pesquisa com a temática ambiental obteve maior percentual no decorrer dos seis anos das edições da Feira. Portanto este trabalho de pesquisa buscou identificar quais são as motivações que acabam promovendo o maior número de pesquisas para a meio ambiente e sociedade, e ainda compreender quais as consequências destes trabalhos no espaço escolar.
\end{abstract}

Palavras-chave: Estratégia de Ensino; Feira do Litoral Paranaense.

1 UFPR Litoral. E-mail: michelle.florida@gmail.com

2 UFPR Litoral. E-mail: reisra@gmail.com

3 UFPR Litoral: E-mail: joucoski@gmail.com

Revbea, São Paulo, V. 14, № 4: 296-304, 2019. 


\section{Introdução}

É consenso que o discurso em relação à educação ambiental no espaço escolar é motivo para amplos debates acerca das metodologias e práticas que, respectivamente, envolvam o estudante na construção de uma consciência crítica e a promoção de uma sociedade sustentável. No entanto, de acordo com Silva, Sammarco e Teixeira (2012, p. 51) "nota-se que o academicismo, por vezes, atrapalha o dinamismo das atividades práticas". Ocorre que, as relações ecológicas vão muito além destas visões acadêmicas e antropocêntricas no que diz respeito às estratégias de ensino, ao contrário disso, elas fazem parte de um ciclo natural e para que possamos compreender tais ciclos dentro do ambiente escolar, faz-se necessárias ações que promovam um diálogo profundo e problematizador do nosso entorno, da nossa cultura, das nossas vivências e da nossa interação com o meio.

Desta maneira, o desafio docente de desenvolver tais práticas, à luz de uma sociedade capitalista, tecnológica, globalizada e mercantilizada, no qual o sujeito é envolvido em um sistema de trabalho, em que Marx (1996, p. 133) ressalta "a superação da alienação dos homens com o trabalho e com o meio exterior (natural) que o cerca é um desafio para a sociedade que objetiva desenvolver-se de forma socialmente sustentável". Entretanto o pensamento marxista, ainda nos propõe a refletir que "a inteligência do homem cresceu à medida que aprendeu a transformar a natureza" (MARX, 1844, pg. 498), e por meio destes movimentos de transformações e interações emergiram novos conhecimentos e culturas. Sachs (2007, p.99) afirma que estes conhecimentos empíricos "geraram práticas de manejo sustentável de recursos por meio de certos estilos culturais de organização produtiva".

Frente a este contexto socioeconômico e educacional, possivelmente, um dos maiores desafios docentes é encontrar estratégias que possam proporcionar curiosidade por parte do estudante ao mesmo tempo em que envolvam a prática social.

Contudo nos propomos neste trabalho de investigação identificar as relações de conhecimentos ambientais, que permeiam as Feiras de Ciências, uma vez que frequentemente nestes espaços as relações de poder, entre professor e estudante, são reduzidas pela autonomia do aluno, pela escolha dos temas geradores dos projetos, e até mesmo pelo formato das acomodações dos espaços das apresentações. Além disso, as Feiras de Ciências constroem um papel fundamental para o docente ao assumir uma postura de mediação dos trabalhos, desconstituindo a ideia do professor como único detentor do conhecimento. Nota-se que as Feiras de Ciências frequentemente são locais de ampla participação e interação entre estudantes, além da possibilidade do professor estar à frente de novos projetos na escola. Silva e Saito (2014) afirmam que estes espaços "expõem o empoderamento dos professores e da comunidade escolar e a valorização do conhecimento e práticas locais, uma vez que os envolvidos sentem-se capazes de expor o que pensam e fazem (p.192)"

revista brasileira educação ambiental 
Neste sentido, este estudo ocorreu a partir de uma análise dos dados da Feira de Ciências do Litoral Paranaense organizada há seis anos pela UFPR Setor Litoral, por meio do Programa de Extensão Laboratório Móvel de Educação Científica (Labmóvel). Participam deste evento escolas públicas de seis municípios litorâneos. Para o levantamento de dados utilizamos a técnica de entrevistas semiestruturadas com os professores da rede estadual paranaense que tiveram a oportunidade de participar das Férias de Ciências. Além das entrevistas, utilizamos ainda as inscrições dos últimos seis anos. Para a efetivação das Feiras de Ciências houve investimentos por meio de chamadas públicas provenientes do Ministério da Ciência Tecnologia e Inovação.

A pesquisa buscou identificar em que medida os trabalhos apresentados promoveram a cidadania ambiental e se os trabalhos vinculados com a temática ambiental proporcionaram maior conhecimento do meio para os estudantes.

\section{Material e métodos}

A proposta de pesquisa deste trabalho surgiu durante o $4^{\circ}$ Encontro de Educação, Comunicação e Ciência (EDUCON) organizado pelo LabMóvel que tinha como proposta inicial conhecer a relevância dos trabalhos de metodologia científica dentro das escolas públicas do litoral do Paraná. A partir deste diagnóstico inicial, apresentar aos professores, grande parte da área de Ciências Naturais, possíveis ações para a construção de projetos de Feiras de Ciências nas escolas públicas do litoral paranaense. Nesta oportunidade estava presente o coordenador da Feira de Ciências do Litoral do Paraná, professor Rodrigo Arantes Reis, e o coordenador da Feira de Ciências do Semiárido Potiguar, professor Felipe de Azevedo Silva Ribeiro, palestrante do evento naquela oportunidade. Em sua apresentação, o professor Felipe ressaltou a importância do desenvolvimento de trabalhos vinculados com a realidade local do estudante e como a criação dos projetos preocupava-se em trabalhar, em profundidade, dentro da realidade das instituições de ensino estaduais, ainda que estas escolas possuam pouca estrutura para pesquisa e/ou produção científica, de forma que o estudante construa um aprendizado a partir das problemáticas do cotidiano. Em entrevista concedida para este trabalho, Felipe relatou que:

Quando o aluno é orientado a pesquisar sobre a própria realidade, o estudante vai deixar de construir um projeto somente expositivo, por exemplo sobre vulcão, que não faz parte do seu contexto, para relatar sobre a dificuldade que encontra todos os dias para chegar à escola ao ter que pular um imenso buraco. Depois de conhecer o local onde vive pode propor mudanças que podem proporcionar maior qualidade de vida. (AZEVEDO, 2016, 31min37s). 
A partir da ideia inicial de investigação, no decorrer de seis anos de Feiras de Ciências, 2011 a 2016, pudemos identificar por meio das inscrições que $57 \%$ dos trabalhos apresentados são vinculados com a temática ambiental, sendo que os demais trabalhos optaram por se inscrever em outras cinco categorias. Além dos dados das inscrições foram efetuadas, e posteriormente transcritas, dez entrevistas direcionadas para os professores que estavam presentes nas Feiras. Para a escolha dos sujeitos da pesquisa foram observadas as frequências em que participaram do evento, além do envolvimento com os estudantes. Já no que diz respeito à exploração dos textos foi utilizada como estratégia metodológica a Análise Textual Discursiva proposta por Moraes e Galiazzi que:

[...] pode ser entendida como o processo de desconstrução, seguido de reconstrução, de um conjunto de materiais linguísticos e discursivos, produzindo-se a partir disso novos entendimentos sobre os fenômenos e discursos investigados. (2011, p. 112)

Desta maneira, surgiram alguns questionamentos que passaram a compor parte das categorias de pesquisa denominadas como categorias a priori ou fechadas, "são aquelas predeterminadas, ou seja, fornecidas de antemão" (MORAES; GALIAZZI, 2011, p. 87). Determinamos uma categorização inicial, que evidenciou uma análise de teor qualitativo e exploratório, uma vez que tínhamos como intuito compreender as relações socioeducacionais que movimentavam estudantes do litoral paranaense na produção de projetos de pesquisa dentro da área ambiental.

Durante o levantamento destes dados, pudemos observar alguns pontos relevantes: a socialização entre os estudantes; a relação do aluno pelo objeto de estudo; a interação sociocultural entre os participantes; as manifestações de mediação entre o professor e aluno. Portanto, após vivenciar o momento da pesquisa de campo e o tratamento dos dados, outras categorias passaram a compor parte do trabalho. De acordo com Moraes e Galiazzi são denominadas categorias emergentes aquelas que "não são previstas de antemão, mas construídas a partir dos dados e informações obtidos das pesquisas" (1999, p.87).

A partir disso, os dados foram transcritos e posteriormente passaram por um processo de unitarização. Seguidamente, o texto foi fragmentado em categorias que geraram unidades de significados provenientes das relações empíricas, teóricas e interpretações dos pesquisadores. Para Bogdan e Biklen (1994, p. 50) "o significado é de importância vital na abordagem qualitativa, uma vez que, os investigadores que fazem uso deste tipo de abordagem estão interessados no modo como diferentes pessoas dão sentido às suas vidas" Durante o último processo, auto-organização e análise foi utilizado o Software "QDA Miner Lite" (PROVALIS 1989). 


\section{Resultados}

O processo analítico teve início a partir dos estudos das inscrições feitas para as Feiras de Ciências ocorridas entre 2011 e 2016. Foi observado que no decorrer dos seis anos de evento participaram estudantes de escolas públicas e privadas de seis municípios litorâneos: Guaratuba, Matinhos, Pontal do Paraná, Morretes, Antonina e Paranaguá. Os eventos contaram com mais de noventa professores da rede estadual de educação. Na última edição da Feira, dez docentes se disponibilizaram para participar desta pesquisa. No que diz respeito aos trabalhos, foram apresentados aproximadamente 377 , de forma que o percentual de projetos vinculados com a temática ambiental foi de $57 \%$, seguidos de trabalhos na área da saúde, com $23 \%$; ciência e experimentações $9 \%$; cultura e sociedade 7\%; e trabalhos voltados para tecnologias, $4 \%$ (Figura 1.

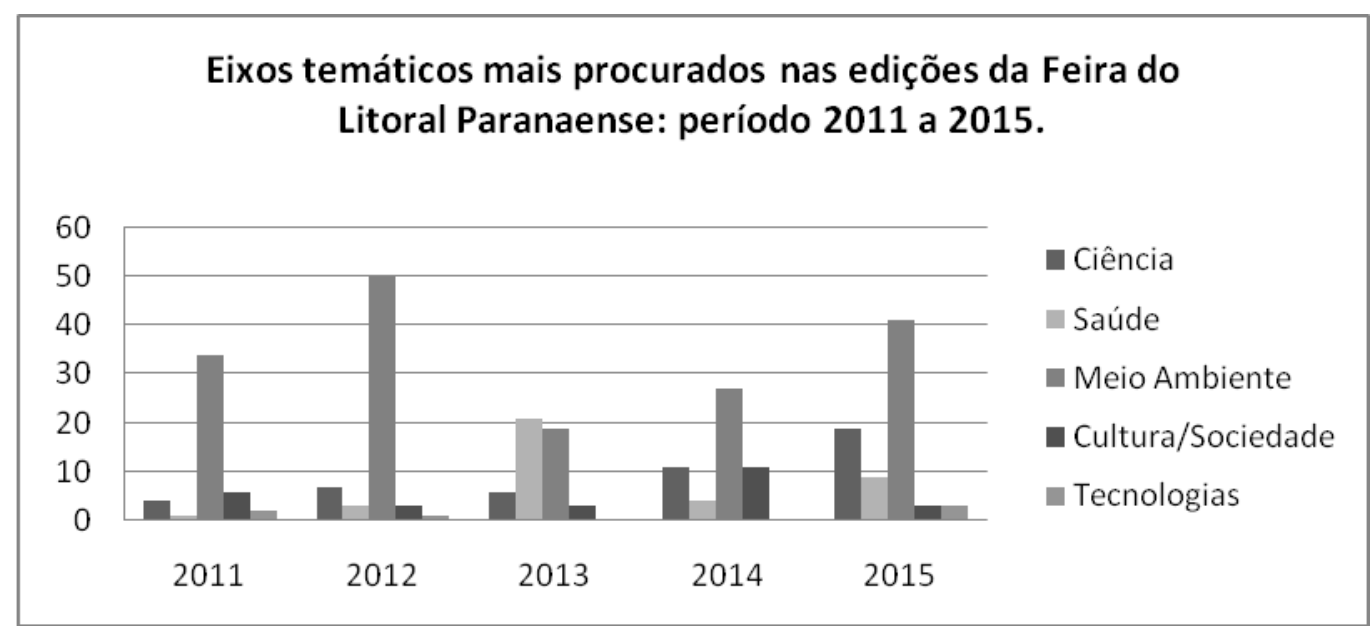

Figura 1: Eixos temáticos mais procurados anualmente. Fonte: Arquivos pessoais dos pesquisadores de acordo com as inscrições das FCs.

Estes dados iniciais contribuíram para a elaboração de dois fatores importantes para esta pesquisa. O primeiro, a elaboração das categorias determinadas como a priores, entre elas: educação ambiental; tema gerador da pesquisa; participação dos docentes nas FCs; interdisciplinaridade e orientação dos trabalhos. A segunda, a construção do questionário aplicado aos professores da rede estadual do Paraná, que tinha como relevância discutir sobre a organização dos trabalhos para a apresentação na Feira do Litoral, e, além disso, como ocorriam as relações em âmbito escolar no que diz respeito o desenvolvimento dos projetos científicos. Após o processo de transcrição e unitarização dos textos, surgiram categorias que estavam intimamente relacionadas com as primeiras, mas que, contudo, organizavam-se em uma nova categoria. De acordo com a metodologia proposta para este trabalho obtivemos desta maneira as categorias emergentes. Seguidamente, após a fragmentação de tais categorias, a priori e emergente, surgiram as unidades de 
significados vindas da interlocução dos relatos dos professores, os objetivos da pesquisa, além da relação empírica dos pesquisadores.

O Quadro I expõe a relação entre a metodologia utilizada, os dados coletados e as interpretações evidenciadas.

Quadro 1: categorias a priores, emergentes e unidades de significados.

\begin{tabular}{|c|c|c|}
\hline $\begin{array}{c}\text { Categorias } \\
\text { a priores }\end{array}$ & Categorias emergentes & Unidades de significados \\
\hline $\begin{array}{l}\text { Educação } \\
\text { Ambiental. }\end{array}$ & Percepção ambiental & $\begin{array}{l}\text { - Interação do aluno com o meio ambiente. } \\
\text { - Alunos identificam as problemáticas ambientais. } \\
\text { - Alunos percebem o seu entorno e os recursos } \\
\text { provenientes desse meio. } \\
\text { - Alunos desenvolvem trabalhos considerando } \\
\text { técnicas sustentáveis na utilização dos recursos } \\
\text { naturais. } \\
\text { - Professores possuem conhecimentos } \\
\text { pertinentes às áreas ambientais e paradigmas } \\
\text { que promovam uma educação crítica. }\end{array}$ \\
\hline $\begin{array}{l}\text { Tema } \\
\text { gerador da } \\
\text { pesquisa. }\end{array}$ & $\begin{array}{l}\text { Autonomia dos estudantes } \\
\text { na escolha do tema de } \\
\text { pesquisa. }\end{array}$ & $\begin{array}{l}\text { - Alunos têm liberdade na escolha dos trabalhos. } \\
\text { - Os temas escolhidos retratam a realidade do } \\
\text { estudante. } \\
\text { - Professores definem o tema de pesquisa. } \\
\text { - Imposição do tema de acordo com a perspectiva } \\
\text { de apresentação em eventos externos. }\end{array}$ \\
\hline $\begin{array}{l}\text { Participação } \\
\text { dos } \\
\text { docentes na } \\
\text { FCs. }\end{array}$ & $\begin{array}{l}\text { Apoio da instituição para } \\
\text { que professores } \\
\text { desenvolvam as FCs. }\end{array}$ & $\begin{array}{l}\text { - Há participação efetiva dos professores nas FCs } \\
\text { - Alunos participam de projetos educacionais } \\
\text { promovidos pela escola. } \\
\text { - Há colaboração da equipe diretiva na } \\
\text { implementação de projetos na escola. }\end{array}$ \\
\hline $\begin{array}{l}\text { Interdisciplin } \\
\text { aridade. }\end{array}$ & $\begin{array}{lc}\text { Ocorre } & 0 \\
\text { interdisciplinar. }\end{array}$ & $\begin{array}{l}\text { - Professores identificam a necessidade de } \\
\text { trabalhos nas diferentes áreas do conhecimento. } \\
\text { - As dificuldades encontradas para trabalhar de } \\
\text { tal forma. }\end{array}$ \\
\hline $\begin{array}{l}\text { Orientações } \\
\text { dos } \\
\text { trabalhos. }\end{array}$ & $\begin{array}{l}\text { Orientações dos trabalhos } \\
\text { - como ocorrem, em que } \\
\text { momento. }\end{array}$ & $\begin{array}{l}\text { - O aluno tem acesso ao orientador. } \\
\text { - Em quais momentos ocorrem às orientações. } \\
\text { - Dificuldades encontradas para o momento de } \\
\text { orientação. }\end{array}$ \\
\hline
\end{tabular}

Entretanto a fim de discutir sobre os temas apresentados no quadro I e compará-los com os relatos dos professores, segue abaixo o quadro que retrata a frequência em que os entrevistados relatavam suas experiências ao trabalhar com as Feiras de Ciências.

O Quadro 2: expõe o relato dos professores de acordo com as entrevistas ocorridas no dia 18/10/2016. 


\section{Educação Ambiental}

\begin{tabular}{|c|c|c|c|c|}
\hline & Contagem & \% Códigos & Casos & $\%$ Casos \\
\hline $\begin{array}{l}\text { Alunos identificam os } \\
\text { ambientais. }\end{array}$ & 7 & $12,0 \%$ & 6 & $100,0 \%$ \\
\hline $\begin{array}{l}\text { Alunos percebem o seu entorno e os } \\
\text { recursos provenientes desse meio. }\end{array}$ & 3 & $5,1 \%$ & 3 & $50,0 \%$ \\
\hline $\begin{array}{l}\text { Professores possuem conhecimentos } \\
\text { pertinentes às áreas ambientais. }\end{array}$ & 4 & $6,8 \%$ & 3 & $50,0 \%$ \\
\hline \multicolumn{5}{|c|}{ Tema gerador dos trabalhos } \\
\hline & Contagem & \% Códigos & Casos & $\%$ Casos \\
\hline $\begin{array}{l}\text { Alunos têm liberdade na escolha dos } \\
\text { trabalhos }\end{array}$ & 7 & $11,9 \%$ & 6 & $100,0 \%$ \\
\hline $\begin{array}{l}\text { Os temas escolhidos retratam a realidade } \\
\text { dos alunos. }\end{array}$ & 3 & $5,1 \%$ & 3 & $50,0 \%$ \\
\hline Professores definem o tema de pesquisa & 2 & $3,4 \%$ & 2 & $33,3 \%$ \\
\hline \multicolumn{5}{|c|}{ Organização das Feiras no espaço escolar } \\
\hline & Contagem & \% Códigos & Casos & $\%$ Casos \\
\hline $\begin{array}{l}\text { Há participação efetiva dos professores } \\
\text { nas FCs }\end{array}$ & 9 & $15,23 \%$ & 5 & $83,3 \%$ \\
\hline $\begin{array}{l}\text { Não há colaboração da comunidade } \\
\text { escolar }\end{array}$ & 1 & $1,7 \%$ & 1 & $16,7 \%$ \\
\hline \multicolumn{5}{|c|}{ Interdisciplinaridade } \\
\hline & Contagem & \% Códigos & Casos & $\%$ Casos \\
\hline $\begin{array}{l}\text { Professores identificam a promoção do } \\
\text { trabalho interdisciplinar para a construção } \\
\text { dos projetos }\end{array}$ & 4 & $6,8 \%$ & 3 & $50,0 \%$ \\
\hline \multicolumn{5}{|c|}{ Orientações dos trabalhos } \\
\hline & Contagem & \% Códigos & Casos & $\%$ Casos \\
\hline O aluno tem acesso ao orientador & 3 & $5,1 \%$ & 3 & $50,0 \%$ \\
\hline $\begin{array}{l}\text { O professor identifica dificuldades para as } \\
\text { orientações (pouco tempo para orientar, } \\
\text { pouca habilidade dos estudantes para } \\
\text { produzir projetos de pesquisas) }\end{array}$ & 7 & $11,9 \%$ & 5 & $83,3 \%$ \\
\hline
\end{tabular}

É relevante ressaltar que para a categoria de educação ambiental, sete professores afirmaram que a construção dos projetos para as Feiras corrobora para que os estudantes identifiquem os problemas ambientais. Entretanto somente três deles acreditam que os alunos reconhecem o seu entorno e os recursos provenientes deste meio natural. Outra importância ao tratar sobre a educação ambiental é decorrente do fato de que apenas quatro professores se sentem preparados para trabalhar com este tema, e que, constantemente atribuíram esta deficiência ao processo de formação.

No que diz respeito aos temas geradores dos trabalhos, sete professores afirmavam a livre escolha dos estudantes, e que frequentemente a escolha da temática estava vinculada com os temas que os estudantes estavam conhecendo dentro do espaço formal.

Ao serem questionados sobre a participação e colaboração dos demais professores na organização de eventos científicos semelhantes às FCs, os sujeitos da pesquisa relataram que grande parte da comunidade escolar 
participa efetivamente, e que percebem o envolvimento do trabalho interdisciplinar. Entretanto, por possuírem maiores conhecimentos nas suas áreas de conhecimento e devido ao pouco tempo para estudos e planejamentos com os demais professores em suas múltiplas áreas, acabam por aproximar os temas às suas formações.

Por último, no que diz respeito às orientações dos trabalhos, um momento de extrema importância para aproximar o aluno ao objeto de estudo, em ampla medida os docentes reiteravam o pouco tempo para organizar e mediar às pesquisas. Demo $(2010$, p.116) relata que o problema maior entre os licenciados é decorrente do fato que seus professores não foram pesquisadores, deste modo tendem fortemente a reproduzir 0 modelo instrucionista e a deformar os alunos.

\section{Considerações finais}

Este estudo aponta para possíveis formas de incluir ao valorizar diferentes formas conhecimento tradicional, uma vez que somos sujeitos sociais, culturais e históricos e nossa relação com o meio é decorrente principalmente das nossas vivências, diferenciando-se de modelos tradicionais e disciplinares. FOUCAULT $(2008$, p.153) ressalta que "a penalidade que controla todos os instantes das instituições disciplinares compara, diferencia, hierarquiza, homogeniza, exclui"

Além disso, os dados aqui apresentados sobre a Feira de Ciências do Litoral Paranaense acenam para a promoção de uma educação ambiental para a cidadania uma vez que os trabalhos apresentados se articulam com temas locais e regionais. Ainda percebemos que o desenvolvimento dos projetos no espaço escolar promove a permanência do processo educativo uma vez que ao conhecer o local onde vive, em um processo de desvelar as relações homem e mundo, emergem ações transformadoras. Freire retrata que nossa relação histórica com o mundo de

[...] estar no mundo sem fazer história, sem por ela ser feito, sem fazer cultura, sem tratar sua música, sem pintar, sem cuidar da terra, das águas, sem usar as mãos, sem esculpir, sem filosofar, sem pontos de vista sobre o mundo, sem fazer ciência ou teologia, sem assombro em face do mistério, sem aprender, sem ensinar, sem ideias, de formação, sem politizar não é possível. (FREIRE, 2013, p.57) 


\section{Referências}

BOGDAN, R.C.; BIKLEN, S.K. Investigação qualitativa em educação. Tradução Maria João Alvarez, Sara Bahia dos Santos e Telmo Mourinho Baptista. Porto: Porto Editora, 1994.

DEMO, P. Educação e Alfabetização Científica. Campinas, SP: Papírus, 2010.

FOUCAULT, M. Vigiar e Punir: nascimento da prisão. Tradução de Raquel Ramalhete. 35 ed. Petrópolis, RJ: Vozes, 2008.

FREIRE, P. Pedagogia da autonomia: saberes necessários à prática educativa. 9. ed. São Paulo: Paz e Terra, 1996.

MARX, K. Manuscritos econômico-filosóficos: primeiro manuscrito.1844. Tradução de Jesus Ranieri. São Paulo: Boitempo Editorial, 2006.

MORAES, R.; GALIAZZI, M. Análise Textual Discursiva. 2 ed. Ijuí, SP: Unijuí, 2011.

MORAES, R.; GALIAZZI, M. O capital: crítica da economia política. Coordenação e revisão de Paul Singer. Tradução de Regis Barbosa e Flávio R. Kothe. São Paulo: Nova Cultural, 1996. (Os Pensadores, livro 1, tomo 2)

PROVALIS. QDA Miner Lite - Free Qualitative Data Analysis Software. Disponível em: <https://provalisresearch.com/products/qualitative-data-analysissoftware/freeware/>.

SACHS, I. Rumo à Ecossocioeconomia: teoria e pratica do desenvolvimento. São Paulo: Cortez, 2007.

SILVA, F.W; SAMMARCO, Y.M; TEIXEIRA, A.F. Educação Ambiental Lúdica: diálogos do corpo, lazer e arte. In: LISBOA, C.P.; KINDEL, E.A.I. Educação Ambiental da teoria á prática. Porto Alegre: Mediação, 2012.

SILVA, M.L; SAITO, C. H. A educação ambiental em comunidades fora de áreas urbanas: aspectos metodológicos. In: PEDRINI, A.G; SAITO, C.H. Paradigmas Metodológicos em Educação Ambiental. Petrópolis, RJ: Vozes, 2014. 